\title{
Multi-angle Quantitative Analysis of Constraints of Sports Economic Development
}

\author{
Lihong Sun \\ College of physical education, Shandong University of Finance and Economics, Jinan Shandong \\ 250014, China.
}

Keywords: Sports Economy, Development, Constraints, Multi - angle, Quantitative Analysis.

\begin{abstract}
Economic education in our country more and more attention by government departments, government departments will sports economy planning for our country in the future economic growth point of growth. In this article, we analyze the constraints that the sports economy faces in the current situation. Combined with the new normalcy of economy and the requirements of supply-side reform, innovation and entrepreneurship, we discussed the path of promoting the development of sports economy.
\end{abstract}

\section{Introduction}

Sports economy means the sum of production, management and service activities associated with sports life and sports activities. Since the reform and opening, with the rapid and long-term economic development in our country, the sports economy has become an important part of the national economy. In this process, people's living standards are continuously improving, and the consumption demand for sports and leisure sports and sports culture is more and more exuberant, which also promotes the rapid development and scientific development of sports economy. Sports economy is different from sports, sport is the focus of social civilization construction and social benefits, sports economy refers to access to economic benefits, that is sports economy is a kind of commercial activities in the socialist market economy. In recent years, the deepening reform of the socialist market economic system has infused a great vitality into the sports economy. In addition, China has regularly held major sports activities both at home and abroad. This has given our sports economy a good foundation and a rare historic opportunity. However, due to the short history of the development of sports economy in our country, combined with the incomplete and incomplete reform of economic system, it faces many constraints. It is an important way for China's sports economy to develop scientifically and improve its international competitiveness under the new situation in-depth analysis of all aspects of the constraints and the targeted crack.

Economic education and sports are different concepts. Sports are more focused on the needs of social and spiritual civilization, while the sports economy is more focused on the acquisition of economic benefits. Sports economy is commercial. The process of economic marketization and the successful hosting of major international and domestic sports events all provide good conditions and unprecedented historical opportunities for the development of our country's sports economy. At the same time, there are also many factors restricting the development of the sports economy. By analyzing the restrictive factors, we can find the corresponding solutions and help the healthy development of the sports economy in our country.

\section{The Proposed Methodology}

\subsection{Factors Restricting the Development of Chinese Sports Economy.}

In developed countries in the West, attaches great importance to the cultivation of social quality of the population, that sports are a lifelong work of the public. Although our country has begun to attach importance to the development of physical quality of the general public, the traditional feudal thinking has made the majority of our people still think that sports are not important. The training of people's physical quality is often the beginning of the vigorous, to the end of it. If our people do not attach importance to physical exercise, it will inevitably affect the development of the entire sports 
economy. This is because people's interests determine their values and values can affect consumer behavior. People are not interested in physical exercise, naturally, will not put considerable economic cost in order to exercise.

Due to the current people's lack of consumption in sports, the lack of such consumption has further affected the demand for sports investment. Therefore, another reason for restricting China's sports economy is that sports investment does not have enough demand, which is also the most important factor restricting the development of China's sports economy. The lack of investment is mainly reflected in the government and enterprises, the government does not attach importance to sports investment, and this lack of attention has further affected the enthusiasm of corporate investors for investment in sports economy.

If we want to develop the sports economy better, we need to cultivate a complex talent who understands sports as well as economy and management. At present, the composition of the managers of the sports economy mainly consists of athletes and coaches who are retired from the field of sports and some who have not implemented employment or laid-off workers. These managers are more familiar with the work in the field of sports, but generally they do not have the managerial skills and the level of running a sports economy. Therefore, in today's sports economy, real sports economic management personnel are severely deficient.

While the development of sports economy, subject to the constraints of the traditional sports system, there is no perfect market management system related to sports economy. In China's traditional sports system, sports events are arranged by the State Sports Commission, which is a planned sports system. In the early days of the beginning of the development of the sports economy, China tried to change this traditional sports system to enterprise behavior. Although this conversion has a certain color of the market economy, it still cannot get rid of the planned economy. Although enterprises get some chances to participate in sports events in this process, the dominance of sports events still lies in the hands of the government. Enterprises do not have sufficient autonomy. This will inevitably affect the enthusiasm of enterprises to invest in sports.

\subsection{The Way to Promote the Development of Chinese Sports Economy.}

Strengthen quality management. The overall improvement of the supply quality of the sports economy means, on the one hand, the enhancement of the value of use in the production of products and provision of services; on the other hand, that the products and services also have social values; specifically, they satisfy the consumer needs of the individual and the society as a whole Consumer trends. In this process, the key factor is to improve the quality of products and services. Strengthening quality management refers to the comprehensive and systematic quality management of the whole process of product production and service in order to improve the quality of products and services, and use advanced management techniques, science and technology, production technology, etc., in order to achieve the strategic goal of enterprise quality and Consumer demand. Under the current situation, it is necessary to firmly establish the overall quality management awareness, vigorously reform the operation mechanism and management system, and promote the transformation of the sports economy to the connotation-oriented development. Efforts should be made to improve the professional standards and quality of the team, vigorously introduce and train specialized personnel, and provide intellectual protection for improving the quality. At the same time, relevant departments should step up enforcement of quality laws and regulations, crack down on counterfeit products and services, create a fair and free market environment, and form a scientific mechanism for the elimination of superiority and superiority.

Vigorously promote "double hit." At present, our country is vigorously advocating the mass innovation of public entrepreneurship. Under the new economic normal, this is an important channel for supply-side reform and an important engine for the development of sports economy. The important content of innovation and entrepreneurship is to improve the quality of product and service supply connotation, and continue to create new sports consumer demand, new areas of products and services, which is conducive to greatly expand the space for sports economic development, enrich the sports economy, and optimize Its industrial structure. At present, in economic development, the demographic dividend of our country is disappearing and the cost advantage is no longer. Under the 
circumstance of insufficient demand in the global market, innovation and entrepreneurship are the turning point and the breakthrough point for the development of the sports economy. Therefore, we must vigorously support innovation and entrepreneurship, create a good environment for innovation and entrepreneurship through fiscal and taxation, financial policies, investment preferences, government guidance and building a platform to enhance the motivation and vitality of innovation and entrepreneurship. Reform the sports economic development system, establish and improve a policy support system for sports economy innovation and entrepreneurship, and encourage and guide the market players to carry out innovation and entrepreneurship. Enterprises must also step up R\&D efforts in science and technology, strive to introduce new models of products and services that meet the needs of development, reposition their business development strategies, and clearly define the strategic objectives and direction of innovation and entrepreneurship.

\subsection{The Improvement of Physical Education.}

The development of sports economy can improve our national literacy and sports consumption needs and can promote the development of sports in our country from an economic point of view. In order to further improve the sports consumption demand of residents in our country, we need to constantly improve the sports literacy of our residents and promote the consumption awareness of our residents. It is necessary to carry out various types of sports activities in the entire people and further enhance the sense of fitness of our residents and the concepts of fitness that our clients need. From the community, rural areas, schools, businesses and other various aspects of the development of sports, in addition, we must also increase the construction of sports facilities in all communities and rural areas, and further increase the number of sports participation population so as to then enhance the level of sports consumption of grass-roots mass organizations in our country.

If we consider from a long-term perspective, we need to mobilize investment power from all aspects of society to form a certain scale of investment in sports economy and to develop a diversified investment structure in sports economy. This diversified sports economy investment layout can arouse the investment enthusiasm of all sectors of society's investment. However, in this process, the government should give full play to its leading role in helping investment enterprises to find hotspots in sports economic investment so as to further maintain the investment enthusiasm of investment enterprises and provide higher return on investment for investment enterprises. At the same time, sport supervisory departments at all levels need to further develop a diversified sports economy and promote the process of sports economy industrialization. Can be considered conditional enterprise management of sports institutions, institutions can be the original state funding into a combination of state funding and social funding. In this way, the development of the sports economy can be carried out from the state to the society. In the course of the development of the sports economy, the investment channels can be diversified and diversified. The combination of primary and secondary can complement each other better Enhance the investment in sports economy and establish a new pattern of sports economy.

In order to effectively promote the development of China's sports economy, government departments should step up their efforts to support the sports economy and formulate a series of effective policies and measures. First, government departments should formulate relevant guidelines and policies that are conducive to the development of sports economy as soon as possible. To follow the example of the developed western countries, give some support to the sports economy on the policy. From the financial and tax policies to give the sports economy a certain discount. For example, revenue from sports venues and donations received by sporting organizations may be reduced or exempt from certain tax revenues. If enterprises sponsor sporting events, they may use the expenses as expenditures or production costs for advertisements of the enterprises. They may also grant land acquisition of sports venues the corresponding preferential policies. Second, we must give full play to the role of general sports departments, try to host sports events from government to governmententerprise cooperation and give full play to the role of enterprises in sports activities. However, during the process of implementation, government departments should give full decentralization of rights. Otherwise, enterprises have no autonomy in organizing sports events. Although many investments cannot be made in exchange for the corresponding return on investment, the enthusiasm of enterprises 
will be greatly reduced. Third, government departments should designate policies that protect the interests of sports investors by specifying a series of investment laws and regulations and financial operating rules to ensure that sports investors can compete fairly under a standardized system of rules and regulations.

\section{Conclusion}

At present, although the sports economy in our country has made great progress, its share in the economy is not enough to meet the changes in market demand. The main reason is the low level of development, the quality of products and services is not high, the brand is weak, these factors are restricting the development of sports economy an important reason. Under the new economic normal, to promote the scientific development of the sports economy must take supply-side reform as a turning point. Innovation and entrepreneurship as the starting point for the development of sports economy to create a good market environment, to give a wide range of policy support. Guide the development of sports enterprises to change thinking, improve brand and quality awareness. Through the simultaneous extension of the extension and connotation, the scale of sports economy will be expanded and the international competitiveness of sports economy will be enhanced.

\section{References}

[1]. Mescam, M., Brossard, J., Vayssiere, N. and Fonta, C., 2017, April. Multi-angle TOF MR brain angiography of the common marmoset. In Biomedical Imaging (ISBI 2017), 2017 IEEE 14th International Symposium on (pp. 1125-1128). IEEE.

[2]. Marassi, V., Roda, B., Casolari, S., Ortelli, S., Blosi, M., Zattoni, A., Costa, A.L. and Reschiglian, P., 2018. Hollow-fiber flow field-flow fractionation and multi-angle light scattering as a new analytical solution for quality control in pharmaceutical nanotechnology. Microchemical Journal, 136, pp.149-156.

[3]. Wang, Y., Li, J. and Wang, H.H., 2017. Cluster and cloud computing framework for scientific metrology in flow control. Cluster Computing, pp.1-10.

[4]. Beckham, K.S., Ciccarelli, L., Bunduc, C.M., Mertens, H.D., Ummels, R., Lugmayr, W., Mayr, J., Rettel, M., Savitski, M.M., Svergun, D.I. and Bitter, W., 2017. Structure of the mycobacterial ESX-5 type VII secretion system membrane complex by single-particle analysis. Nature microbiology, 2(6), p.17047.

[5]. Zareapoor, M., Shamsolmoali, P., Jain, D.K., Wang, H. and Yang, J., 2017. Kernelized support vector machine with deep learning: an efficient approach for extreme multiclass dataset. Pattern Recognition Letters. 